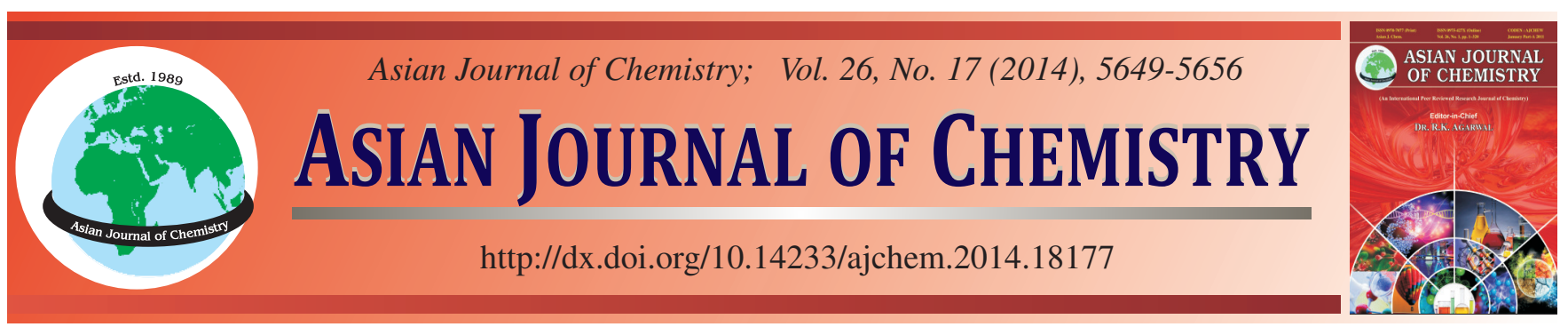

\title{
Analysis of Fracture Mechanics of Glued Laminated Lumber Composed of China's Plantation Wood $\dagger$
}

\author{
Zhong-Feng Zhang ${ }^{1}$, Kai Hung ${ }^{1}$, Yong-Jun Ye ${ }^{1}$, Jun-You $\mathrm{SHI}^{2}$ and Xu Zhang ${ }^{1, *}$
}

${ }^{1}$ Central South University of Forestry and Technology, Changsha 410004, P.R. China

${ }^{2}$ Beihua University, Jilin 132013, P.R. China

*Corresponding author: E-mail: csfuzx@126.com

\begin{abstract}
Increasingly, glued laminated wood, commonly referred to as Glulam, is being produced from Chinese plantation wood, the fracture behaviour of which is the key factor for meeting the requirements for being used as engineered wood for bridges. Both whole factor test methods and nonlinear finite element analyses were used to analyze the fracture mechanics of Chinese Glulam. Test results showed that the fracture modes were initially sliding breaks and then tearing under vertical loads and open fractures under parallel loads. The fracture modes had no correlation to the reinforcing materials under parallel loading and it was realistic for glued laminated lumber to support weight under vertical loading. The simulation results of the nonlinear finite elemental analysis showed that the aluminum foil and glass fiber cloth used in Glulam had an obvious reinforcing effect and both the thickness and length had an interactive effect on the ultimate bearing capacity. It was also seen that the simulation results were consistent with the test results.
\end{abstract}

Keywords: China's plantation wood, Glued laminated lumber, Finite element analysis, Fracture mechanics.

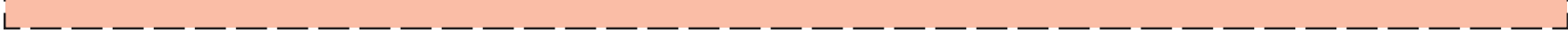

\section{INTRODUCTION}

China's wood industry relies heavily on plantation wood that primarily consists of poplar, eucalyptus and pine trees and covers an area of more than 800 million mu. Nonetheless, plantation wood has a low efficiency level due to the lack of processing technology ${ }^{1,2}$. With the rapid growth of the Chinese economy, there is an urgent need for high quality Glulam for such uses as wooden bridges, renovations of old buildings, field fortifications and other engineering developments. Although plantation trees in China grow rapidly, they have low strength and their extractives interfere with wood glue ${ }^{3-5}$, leading to the bond quality of the Glulam being unable to meet customary requirements. Consequently, the reinforcement of plantation wood is not only the key to manufacturing high quality Glulam, but also the technical core of improving the value of plantation wood.

It has a longer period for the application of Glulam in the field of building structural engineering ${ }^{6-9}$. Bridges generally have long spans and the bearing strength and rigidity of Glulam cannot meet the requirements for bridge engineering ${ }^{10-13}$. A review of the existing literature on Glulam shows that both processing and reinforcement are research priorities ${ }^{14-18}$.
Unfortunately, the study of fracture behaviour of glued laminated lumber made of China's plantation wood is superficial and its use in large span wooden bridge engineering has not been researched. In light of these deficiencies, this study explored fracture behaviours using whole factor tests and nonlinear finite element analysis of Glulam, which was made up of plantation eucalyptus wood veneers reinforced with glass fiber cloth and aluminum foil. The achievements in this study have the potential to provide theories and technical support for manufacturing high quality Glulam and improving the value of plantation wood.

\section{EXPERIMENTAL}

Test materials: The size of eucalyptus wood veneer is $1.27 \mathrm{~m} \times 0.64 \mathrm{~m} \times 1.3 \mathrm{~mm}$ and the density is about $0.61 \mathrm{~g} / \mathrm{cm}^{3}$, with a moisture content of $5-8 \%$. The thickness of aluminium foil is $0.05 \mathrm{~mm}$, the type is aluminum alloy 1060 with a density of $2.71 \mathrm{~g} / \mathrm{cm}^{3}$, a tensile strength of $\geq 75 \mathrm{MPa}$ and the offset yield strength is $\geq 35 \mathrm{MPa}$. The A component of the epoxy adhesive is a milky white or grayish white sticky liquid and the $\mathrm{B}$ component is a yellow-brown or red-brown sticky liquid, with an applicable period of $1 \mathrm{~h}\left(25^{\circ} \mathrm{C}\right)$, curing speed of 2.5 $3.5 \mathrm{~h}\left(25^{\circ} \mathrm{C}\right)$ and the tensile shear strength of $\geq 8 \mathrm{MPa}\left(25^{\circ} \mathrm{C}\right.$ 
$\times 48 \mathrm{~h}$ ). Glass fiber cloth is plain weave, with a warp and weft density of $128 \times 68$.

Design proposals of specimens: The design proposals of the samples are shown in Table-1. There are three parallel specimens in each test group and five test groups in total. The enhanced effect of the glass fiber cloth was obtained through the comparison of groups A1, A2, A 3 and A5 and the enhanced effect of the aluminum foil was obtained through the comparison of groups A1, A2, A4 and A5.

Test methods: According to the assembly patterns shown in Table-1, the specimens were made with a double spread of $350 \mathrm{~g} / \mathrm{cm}^{2}$, put into the cold press with a temperature of about $20{ }^{\circ} \mathrm{C}$ and then pressurized to $4 \mathrm{MPa}$ rapidly and maintained for $1 \mathrm{~h}$. After that, the power source was turned off and the specimens were left in the press for $23 \mathrm{~h}$. The areas obtained from the samples were $350 \mathrm{~mm} \times 350 \mathrm{~mm}$. A typical section of the Glulam is shown in Fig. 1. The specimens were made and tested according to "Standard for Methods of Testing Timber Structures" (GB/T 50329-2002) and "Standard for Methods of Testing Plywood" (GB 9846-2004). The specimens for testing MOR and MOE were 300mm in length by $50 \mathrm{~mm}$ in width. They were loaded to failure at the rate of $10 \mathrm{~Pa} / \mathrm{s}$ and the loading methods were performed according to "Test methods of evaluating the properties of wood-based panels and surface decorated wood-based panels" (GB/T 17657-1999). The results of the tests conducted with parallel and vertical loads are shown in Fig. 2.

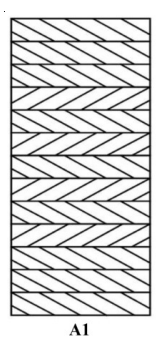

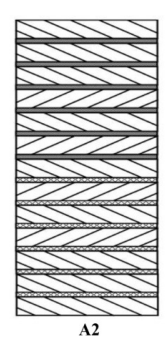

Fig. 1. Typical section of Glulam

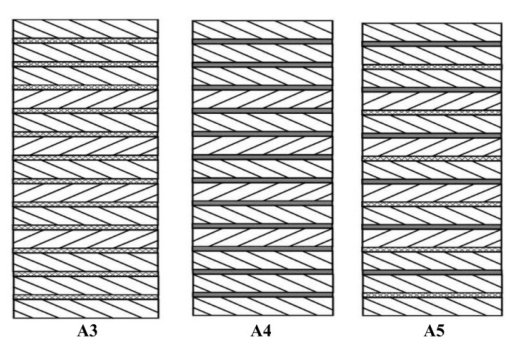

\section{RESULTS AND DISCUSSION}

Fracture structure of Glulam: In the process of the vertical load tests, groups A1-A5 showed some dislocations from the adhesive layers at first and then the cracks expanded to the reinforcing glass fiber cloth and aluminum foil and finally expanded to the wood veneers. According to the fracture structures shown in Fig. 3, the mode was initially the sliding

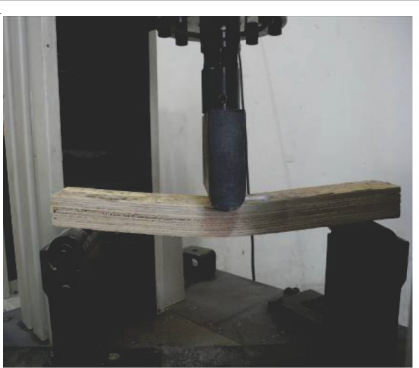

Vertical loading

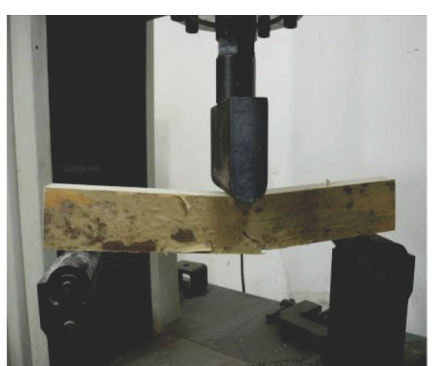

Parallel loading
Fig. 2. Loading methods

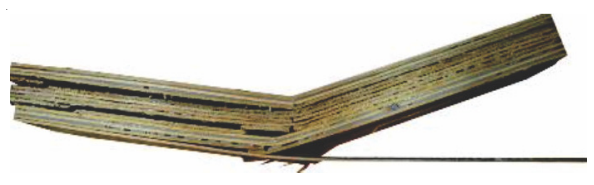

A1

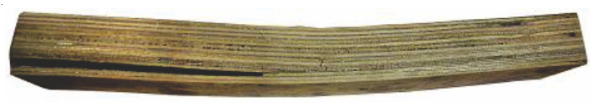

A2

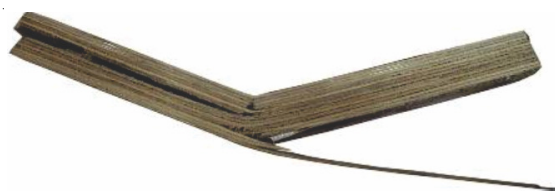

A3
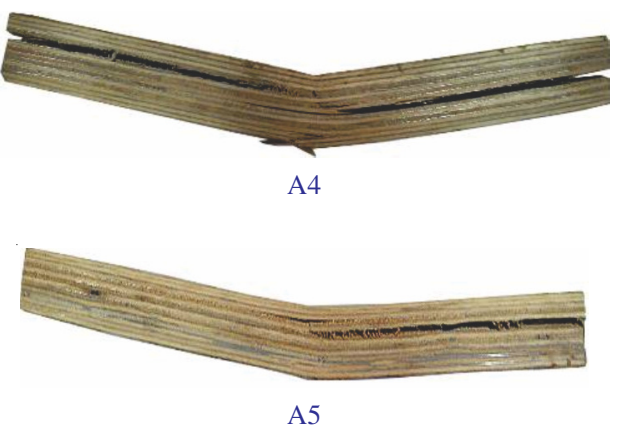

Fig. 3. Fracture structures of Glulam under vertical loading

type, followed by tearing under vertical loading, which resulted from the wood fibers splitting from each other. An epoxy resin presented a three-dimensional network structure and after solidifying at low temperature, the stress and deformation increased at the same time during load testing. The glass fiber

\begin{tabular}{|c|c|}
\hline & $\begin{array}{l}\text { TABLE-1 } \\
\text { DESIGN PROPOSALS OF SPECIMENS }\end{array}$ \\
\hline Test group & Assembling pattern \\
\hline A1 & $\begin{array}{l}\text { The central seven layers of veneers with a criss-cross assembling structure, the outer three layer veneers with paralleled } \\
\text { assembling structure. }\end{array}$ \\
\hline A2 & $\begin{array}{l}\text { The central seven layers of veneers with a criss-cross assembling structure, the outer three layers of veneers with paralleled } \\
\text { assembling structure and glass fiber cloth placed every two veneers making up one half of the Glulam and aluminum foil placed } \\
\text { every two veneers making up the other half. }\end{array}$ \\
\hline A4 & $\begin{array}{l}\text { The central seven layers of veneers with a criss-cross assembling structure, the outer three layers of veneers with paralleled } \\
\text { assembling structure and aluminum foil placed every two veneers. }\end{array}$ \\
\hline A5 & $\begin{array}{l}\text { The central seven layers of veneers with a criss-cross assembling structure, the outer three layers of veneers with paralleled } \\
\text { assembling structure and glass fiber cloth and aluminum foil interval distributed among every two veneers. }\end{array}$ \\
\hline
\end{tabular}


cloth surrounded by epoxy resin showed a reinforcement effect, resulting in the increase of stress on the epoxy resin layer. The areas of the epoxy resin layer with low bond strength appeared to dislocate under the external force. Aluminum, a kind of soft metal, showed good ductility and was not easy to break under external force and had good fracture toughness, but the thickness of the reinforcing aluminum foil was very thin. This led to the aluminum foil nearly dislocating from the epoxy resin.

Wood is a kind of natural polymer fiber material, the fracture of which is decided by microscopic cell structures. The crack propagation method of horizontal wood grain Mode I is a crack extension, initially along the direction of the fibers and then ductile fractures along the cross-section. The total extension process can be divided into three stages: linear, steady and unsteady. The breaking tenacity of a grain crack has nothing to do with the specimen size and is connected to the inherent nature of timber. Wood is strong in the direction of the cross-section because of its many cells and fibers reinforcing the multi-layer cell wall structures. Therefore, the fracture model showed tearing in the last stages of failure, which was the result of the wood fibers tearing. In the process of the parallel load tests, groups A1-A5 specimens were characterized with open fractures. However, the morphological structures were smaller under parallel loading than under vertical loading, as shown in Fig. 4. In addition, the fracture form of Glulam had no impact on the reinforcing material under parallel loading.

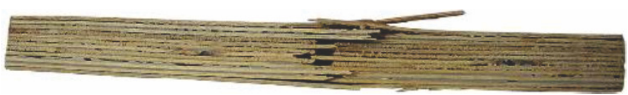

A1

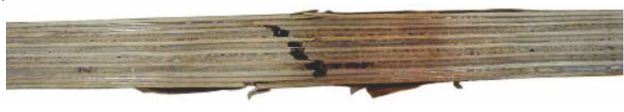

A2

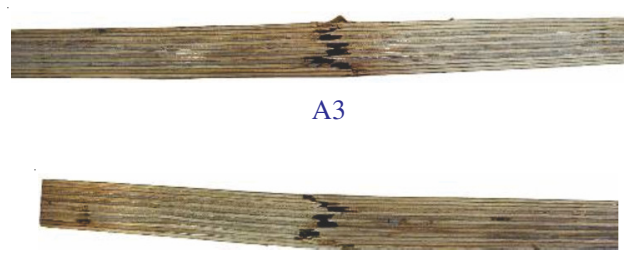

A4

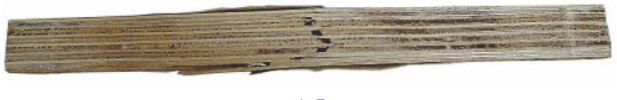

A5

Fig. 4. Fracture structures of Glulam under parallel loading

Breaking strength of Glulam: Load-displacement curves in the process of the fractures are shown in Figs. 5 and 6.

Figs. 5 and 6 show that the A1-A5 group specimens presented linear plastic deformations before they fractured, whether under vertical loads or parallel loads. The fractures formed in a relatively straight line under parallel loading, which related to the brittle fracture, while the fractures formed under vertical loading were fiber fractures, which were due to the

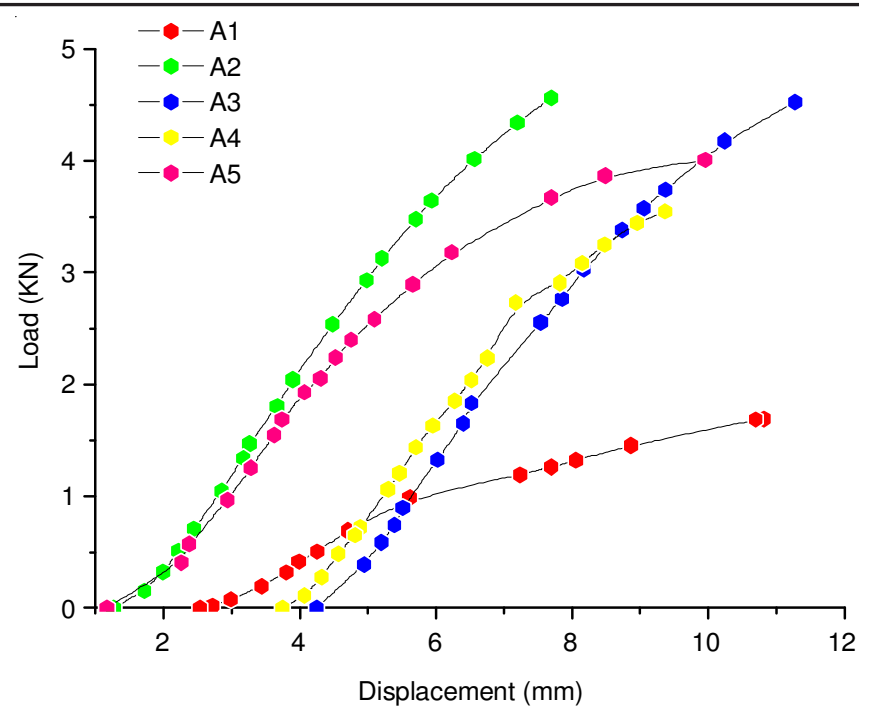

Fig. 5. Load-displacement curves under vertical loading

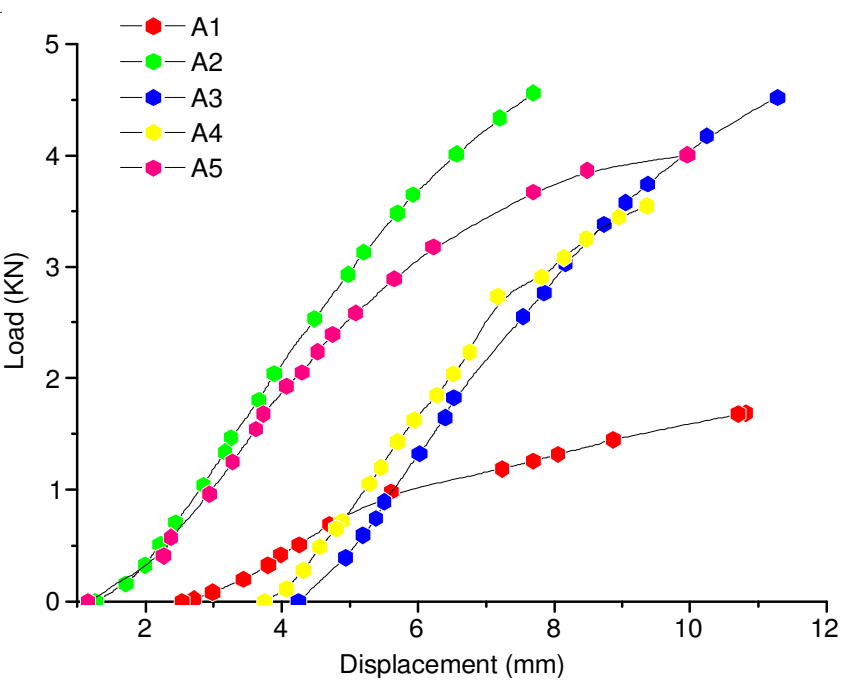

Fig. 6. Load-displacement curves under parallel loading

wood fibers tearing. The A1, A2, A3, A4 and A5 group fracture displacements were 8.286, 6.425, 8.791, 5.62 and $7.036 \mathrm{~mm}$, respectively under vertical loading, while the parallel loading displacements were 5.803, 6.421, 6.007, 4.988 and $5.568 \mathrm{~mm}$, respectively. According to the above data, the bending fracture spacing ratios of the A1-A5 specimens were 30.2, 22.3, 31.7, 21.7 and $28.0 \%$, respectively, under vertical loading. Under parallel loading, the ratios were 11.5, 12.8, 11.4, 9.9 and 11.0 $\%$, respectively. In other words, the fracture displacement under vertical loading was twice as much as it was under parallel loading. This shows that the stress on the specimen increases dramatically and then it easily develops brittle fractures under parallel loading. This material is not recommended for bridge engineering, because of the risk of brittle factures under parallel loading. On the other hand, the accumulation of stress on the specimen causes large displacement, so the damage is obvious before it completely fractures under vertical loading. This is advantageous to finding the damage and taking measures to avoid devastating problems before they occur. When the load reaches the maximum value and begins to decline, the down trend is rapid, which resembles the wood's fracture behaviour. The bearing capacity of the specimens fell sharply after it 
fractured under parallel loading, as shown in Fig. 7. Therefore, it is much better to adopt methods of vertical loading to make timber structures safe.
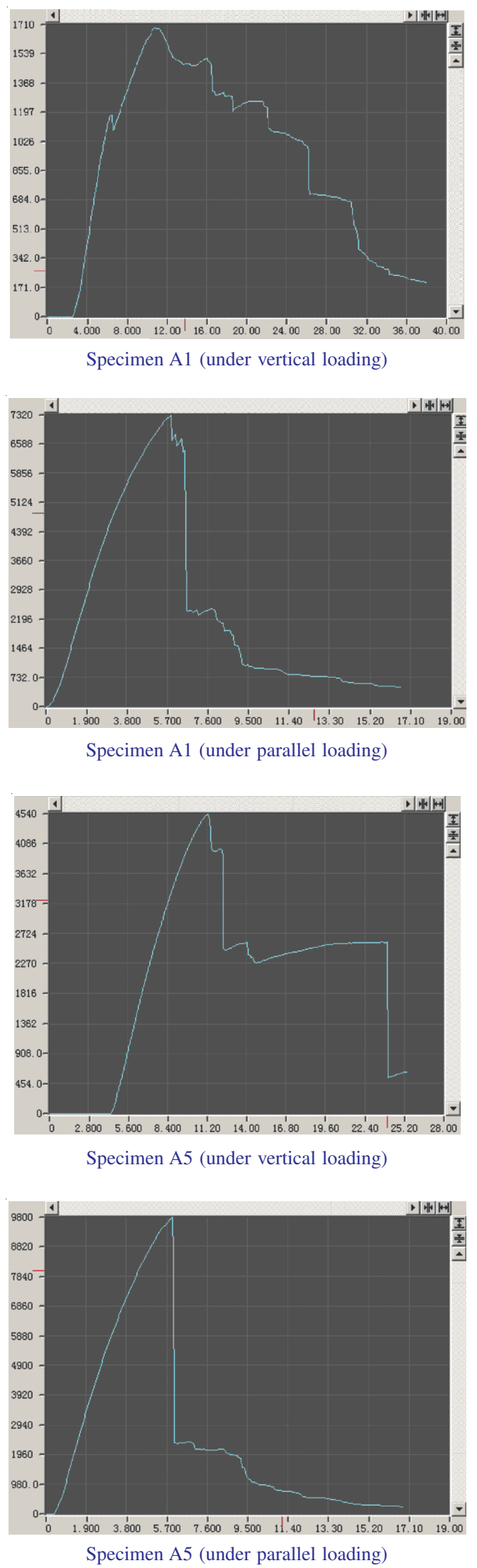

Fig. 7 Curves of fracture processes of typical specimens ( $\mathrm{Y}$ axis means load and $\mathrm{X}$ axis means displacement)
Nonlinear finite element numerical simulation analysis of gulam: Glulam can be viewed as a kind of layer-combinedboard which is a composite formed by a single layer of wood that includes various isotropic or anisotropic materials. In present study, five kinds of Glulam specimens were designed which were composed of wood veneers with criss-cross structures and reinforcing materials of aluminum foil and glass fiber cloth. Because the Glulam was made up of a variety of materials, its mechanical properties had some novel characteristics, such as the obvious anisotropy and nonlinearity. Consequently, it was necessary to set up a mechanical model which could adapt and a corresponding accurate rule between stress-straindisplacement when the materials were under maximum loads, which is the basis of studying the fracture mechanics. Then, the constitutive relativities were input into the material nonlinear finite element program, which is able to perform stress analysis on more complex components or structures and reinforcement methods to inhibit the fracturing of Glulam were explored.

Material nonlinear finite element theory analysis: In nonlinear finite element analysis, material stress-strain relativity should be established first for anisotropic materials (wood fibers), namely the material constitutive relation and a failure criteria should be established to estimate the material yield damage. Then, the constitutive relations and failure estimate criteria should be input into the nonlinear finite element program to analyze the mechanical properties of the Glulam.

Constitutive model: According to the material nonlinearity of Glulam, the elastic-plastic constitutive relation could be used. But, many concepts of elastic-plastic theory are based on the stress-strain curve from the material uniaxial tension and compression tests and then spread to the twodimensional or three-dimensional stress-strain conditions. Taking the ideal uniaxial compressive stress-strain curve of Glulam (Fig. 8). The model included four basic stages of constitutive relation: linear elastic stage, elastic-plastic stage, brittle stage and ductile failure stage. After the elastic stage, material loses efficacy in two forms: Mode 1, which is called brittle failure and Mode 2, which means strain after the material enters the plastic stage and with the increase of strain, material finally loses efficacy in the form of ductile or brittle fractures. For ductile fractures, the material generally loses all stiffness but keeps its bearing strength, while during the brittle failure it loses all of its stiffness and strength. Its strain strengthening is defined sustained growth of the yield surface based on the rheological and isotropic reinforcing. The yield surface defined in this research follows the Tsai-Wu tensor strength criterion, which is explained below.

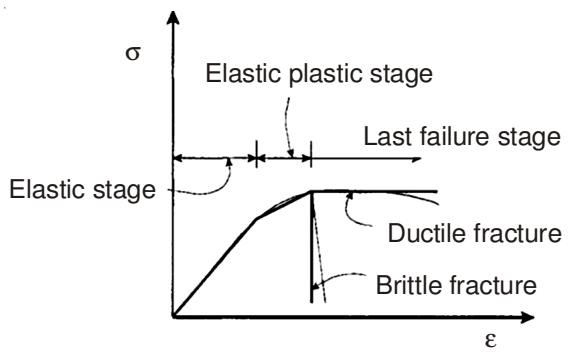

Fig. 8. Ideal uniaxial compressive stress-strain curve of Glulam 
Fig. 7 shows the typical Glulam specimen load-displacement curves in the fracture process under vertical and parallel loading. It was observed that the specimens ultimately lost efficacy in the form of brittle fractures whether under vertical loading or parallel loading. In this research, the uniaxial compressive stress-strain curve of Glulam was adopted, including the linear elastic stage, elastic-plastic stage and brittle failure stage.

Tsai-Wu failure criterion: Glulam is a kind of layercombined-board which is a composite single layer board. In this study, five kinds of Glulam specimens were designed which were composed of wood veneers with a criss-cross assembling structure and reinforcing aluminum foil and glass fiber cloth. The fiber arrangements in every layer were not the same, which can cause deformations, unlike those produced by mechanical effects, in each layer. Therefore, finding the final mechanical properties is a very complicated problem and its complexity is embodied in the following two aspects:

(1) The stress complexity of a mesoscopic structure. The mechanical properties of glued laminated material depend on the performance of the reinforcing aluminum foil and glass fiber cloth, the volume rate and direction of the wood fiber bundle, the surface processing of the wood fiber, the adhesive and interface conditions, the elongation and toughness of the matrix, the craft process and quality, the curing temperature, the temperature and humidity in the working environment, the stress distribution and loading time and rate, etc.

(2) The diversity of the forms of macroscopic damage. The failure modes of Glulam are related to the various damage types of the component materials. Possible failure modes include fracture of the wood fiber bundle, a buckling of the wood fibers, cracking of the matrix, delamination, de-bonding of the interface, overall and local buckling failure and overall fracture damage.

With the wide application of composite materials, many scholars use strength criterion of isotropic materials with new forms used in composite materials. These strength criterions are the greatest stress (strain) criterion: the Tsai-Hill criterion, the Hoffman criterion and specific strain energy-density criterion $^{19,20}$. Using a combination of the many strength criterions, Tsai and $\mathrm{Liu}^{21}$ suggested the tensor form of strength theory. The Tsai-Wu tensor criterion is the most comprehensive in describing composite material damage and other criterion can be derived by simplifying this method according to the specific conditions of load and stress. Tsai and $\mathrm{Liu}^{21}$ concluded the original failure criterion to a higher-order tensor polynomial criterion and its general form is as follows:

$$
\mathrm{F}_{\mathrm{i}} \sigma_{\mathrm{i}}+\mathrm{F}_{\mathrm{ij}} \sigma_{\mathrm{i}} \sigma_{\mathrm{j}}+\mathrm{F}_{\mathrm{ijk}} \sigma_{\mathrm{i}} \sigma_{\mathrm{j}} \sigma_{\mathrm{k}}+\cdots=1(\mathrm{i}, \mathrm{j}, \mathrm{k} \cdots=1,2, \cdots, 6)
$$

In eqn. $1, \sigma_{i}, \sigma_{j}$ and $\sigma_{k}$ are the stress vectors and $F_{i}, F_{i j}$ and $F_{i j k}$ are the intensity parameters of the material, respectively. They are symmetric tensors and can usually be obtained through experiment. In engineering design, in order to avoid the higher test expenses caused by determining the tensor coefficient, the first two terms are usually taken to obtain the result to meet the required precision. That is:

$$
\mathrm{F}_{\mathrm{i}} \sigma_{\mathrm{i}}+\mathrm{F}_{\mathrm{ij}} \sigma_{\mathrm{i}} \sigma_{\mathrm{j}}=1
$$

For one-way slab in a state of plane stress, $\mathrm{i}, \mathrm{j}, \mathrm{k} \ldots=1,2$, 6 and eqn. 2 can be written in matrix form as follows:

$$
\left\{\begin{array}{lll}
\mathrm{F}_{1} & \mathrm{~F}_{2} & \mathrm{~F}_{6}
\end{array}\right\}\left\{\begin{array}{l}
\sigma_{1} \\
\sigma_{2} \\
\sigma_{6}
\end{array}\right\}+\left\{\begin{array}{lll}
\sigma_{1} & \sigma_{2} & \sigma_{6}
\end{array}\right\}\left[\begin{array}{lll}
\mathrm{F}_{11} & \mathrm{~F}_{12} & \mathrm{~F}_{16} \\
\mathrm{~F}_{21} & \mathrm{~F}_{22} & \mathrm{~F}_{26} \\
\mathrm{~F}_{16} & \mathrm{~F}_{26} & \mathrm{~F}_{66}
\end{array}\right]\left\{\begin{array}{l}
\sigma_{1} \\
\sigma_{2} \\
\sigma_{6}
\end{array}\right\}=1
$$

For the reason that the change in the direction of the shear stress $\sigma_{6}\left(\tau_{12}\right)$ will not affect the strength of the material in the main direction coordinate system of the material, the corresponding strength coefficient of the first degree item of shear stress in the equation should be zero, which is as follows:

$$
\mathrm{F}_{6}=\mathrm{F}_{16}=\mathrm{F}_{26}=0
$$

Put eqn. 4 into eqn. 3 to obtain the following result:

$$
\mathrm{F}_{1} \sigma_{1}+\mathrm{F}_{2} \sigma_{2}+\mathrm{F}_{11} \sigma_{1}^{2}+\mathrm{F}_{22} \sigma_{2}^{2}+\mathrm{F}_{66} \sigma_{6}^{2}+2 \mathrm{~F}_{12} \sigma_{1} \sigma_{2}=1
$$

In eqn. 5 , the first five strength parameters can be obtained through uniaxial tension and compression and shear tests along the main direction of the material:

$\mathrm{F}_{1} \mathrm{X}_{\mathrm{t}}+\mathrm{F}_{11} \mathrm{X}_{\mathrm{t}}^{2}=1 \quad$ (only $\sigma_{1}>0$,

The rest of the stress components are zero)

$-\mathrm{F}_{1} \mathrm{X}_{\mathrm{c}}+\mathrm{F}_{11} \mathrm{X}_{\mathrm{c}}^{2}=1 \quad$ (only $\sigma_{1}<0$,

The rest of the stress components are zero)

$\mathrm{F}_{2} \mathrm{Y}_{\mathrm{t}}+\mathrm{F}_{22} \mathrm{Y}_{\mathrm{t}}^{2}=1 \quad$ (only $\sigma_{2}>0$,

The rest of the stress components are zero)

$$
-\mathrm{F}_{2} \mathrm{Y}_{\mathrm{c}}+\mathrm{F}_{22} \mathrm{Y}_{\mathrm{c}}^{2}=1 \quad \text { (only } \sigma_{2}<0 \text {, }
$$

The rest of the stress components are zero)

$$
\mathrm{F}_{66} \mathrm{~S}^{2}=1 \quad\left(\text { only }_{6}\left(\tau_{12}\right) \neq 0,\right.
$$

The rest of the stress components are zero)

From eqn. 6, the strength parameters $F_{i}$ and $F_{i j}$ can be obtained:

Put eqn. 7 into eqn. 5 and then:

$$
\left\{\begin{array}{c}
\mathrm{F}_{1}=\frac{1}{\mathrm{X}_{\mathrm{t}}}-\frac{1}{\mathrm{X}_{\mathrm{c}}}, \quad \mathrm{F}_{11}=\frac{1}{\mathrm{X}_{\mathrm{t}} \mathrm{X}_{\mathrm{c}}} \\
\mathrm{F}_{2}=\frac{1}{\mathrm{Y}_{\mathrm{t}}}-\frac{1}{\mathrm{Y}_{\mathrm{c}}}, \quad \mathrm{F}_{22}=\frac{1}{\mathrm{Y}_{\mathrm{t}} \mathrm{Y}_{\mathrm{c}}} \\
\mathrm{F}_{66}=\frac{1}{\mathrm{~S}^{2}}
\end{array}\right.
$$

Simplify eqn. 8 and then the Hoffman criterion can be obtained:

$$
\begin{gathered}
\frac{\sigma_{1}^{2}}{X_{t} X_{c}}+\frac{\sigma_{2}^{2}}{Y_{t} Y_{c}}+\frac{X_{t}-X_{c}}{X_{t} X_{c}} \sigma_{1}+\frac{Y_{c}-Y_{t}}{Y_{t} Y_{c}} \sigma_{2} \\
+2 F_{12} \sigma_{1} \sigma_{2}+\frac{\tau_{12}^{2}}{S^{2}}=1
\end{gathered}
$$

The rest coefficient of $\mathrm{F}_{12}$ reflects the interaction effect between the tension-compression strengths in the main direction of 1 and 2, which cannot be obtained by uniaxial tests, but can be obtained by biaxial tensile tests.

Assume $\sigma_{1}=\sigma_{2}=\sigma_{0}$ and $\sigma_{6}=0$ and put them into eqn. 5 . Then: 


$$
\left(\mathrm{F}_{1}+\mathrm{F}_{2}\right) \sigma 0+\left(\mathrm{F}_{11}+\mathrm{F}_{22}+2 \mathrm{~F}_{12}\right) \sigma_{0}^{2}=1
$$

And $\mathrm{F}_{12}$ can be obtained:

$$
\begin{array}{r}
F_{12}=\frac{1}{2 \sigma_{0}^{2}}\left[1-\left(\frac{1}{X_{t}}-\frac{1}{X_{c}}+\frac{1}{Y_{t}}-\frac{1}{Y_{c}}\right) \sigma_{0}\right. \\
\left.-\left(\frac{1}{X_{t} X_{c}}+\frac{1}{Y_{t} Y_{c}}\right) \sigma_{0}^{2}\right]
\end{array}
$$

So, $\mathrm{F}_{12}$ not only depends on the basic strength, but is also related to the bidirectional tensile strength $\sigma_{0}$. This parameter can be obtained by biaxial tensile tests, which is the advantage of the Tsai-Wu theory and different from the other criterions. However, this theory also has shortcomings, such as the parameter being very sensitive to the variability of the test and a small error of the intensity parameter may cause a large variation in the parameter value. Therefore, the limiting condition for the parameter value must be introduced.

On the other hand, when the stress increases to a certain point, the material will be destroyed. Therefore, in the stress space, eqn. 5 should be a closed limit surface called the strength envelope surface and the intersecting line with the plane $\sigma_{6}=$ 0 is as follows:

$$
\mathrm{F}_{1} \sigma_{1}+\mathrm{F}_{2} \sigma_{2}+\mathrm{F}_{11} \sigma_{1}^{2}+\mathrm{F}_{22} \sigma_{2}^{2}+2 \mathrm{~F}_{12} \sigma_{1} \sigma_{2}=1
$$

Eqn. 12 should be a closed curve. According to the property of the quadratic curve, it should be an ellipse and there should be the following relations between the coefficients:

$$
\begin{gathered}
\mathrm{F}_{11} \mathrm{~F}_{22}-\mathrm{F}_{12}^{2}>0 \\
-1<\mathrm{F}_{12}^{*}=\frac{\mathrm{F}_{12}}{\sqrt{\mathrm{F}_{11} \mathrm{~F}_{22}}}<1
\end{gathered}
$$

This is the value scope of $\mathrm{F}^{*}{ }_{12}$. For simplicity, make $\mathrm{F}^{*}{ }_{12}$ $=-0.5$ or 0 and the calculation results of most composite materials show that the difference is within $10 \%$ of $\mathrm{F}^{*}{ }_{12}=$ -0.5 and $\mathrm{F}^{*}{ }_{12}=0$.

Plastic formula for orthotropic material: The quadratic failure criterion of orthotropic plastic material yield can usually be represented as follows:

$$
\mathrm{f} \equiv \mathrm{M}_{\mathrm{ij}}\left(\sigma_{\mathrm{i}}-\alpha_{\mathrm{i}}\right)\left(\sigma_{\mathrm{j}}-\alpha_{\mathrm{j}}\right)-\mathrm{k}^{2}=0,(\mathrm{i}, \mathrm{j}=1,2,6)
$$

In eqn. $15, M_{i j}$ is the failure surface, $\sigma_{i}=\left\{\alpha_{1}, a_{2}, 0\right\}$ is the surface's initial value and $\mathrm{k}$ is the stress threshold. Put $\mathrm{L}_{\mathrm{i}}=$ $2 \mathrm{M}_{\mathrm{ij}} \alpha_{\mathrm{j}}, \mathrm{K}=-\mathrm{M}_{\mathrm{ij}} \alpha_{\mathrm{i}} \alpha_{\mathrm{j}}+\mathrm{k}^{2}$ into eqn. 15 to obtain:

$$
\mathrm{f} \equiv \mathrm{M}_{\mathrm{ij}} \sigma_{\mathrm{i}} \sigma_{\mathrm{j}}-\mathrm{L}_{\mathrm{i}} \sigma_{\mathrm{i}}-\mathrm{K}=0
$$

It can be obtained from eqns. 5 and 16 :

$$
\mathrm{M}_{\mathrm{ij}} \equiv \mathrm{KF}_{\mathrm{ij}} \equiv \mathrm{K}\left[\begin{array}{ccc}
\mathrm{F}_{12} & \mathrm{~F}_{12} & 0 \\
& \mathrm{~F}_{22} & 0 \\
\mathrm{sym} & & \mathrm{F}_{66}
\end{array}\right] ; \quad \mathrm{L}_{\mathrm{i}} \equiv-\mathrm{KF}_{\mathrm{i}}=-\mathrm{K}\left[\begin{array}{c}
\mathrm{F}_{1} \\
\mathrm{~F}_{2} \\
\mathrm{~F}_{3}
\end{array}\right](17)
$$

It is obvious that each item of $\mathrm{M}_{\mathrm{ij}}$ is not independent. For example, supposing that $\mathrm{M}_{11}=1$, then $\mathrm{K}=1 / \mathrm{F}_{11} ; \mathrm{M}=\mathrm{F}_{12} / \mathrm{F}_{11}$ and $\alpha_{i}$ also can be obtained synchronously by solving the below equation:

$$
\mathrm{L}_{\mathrm{i}}=-\mathrm{KF}_{\mathrm{i}}=2 \mathrm{M}_{\mathrm{ij}} \alpha_{\mathrm{j}}=2 \mathrm{KF}_{\mathrm{ij}} \alpha_{\mathrm{j}} \Rightarrow \mathrm{F}_{\mathrm{i}}=-2 \mathrm{~F}_{\mathrm{ij}} \alpha_{\mathrm{j}}
$$

So the square of the stress threshold can be represented as follows:

$$
\mathrm{k}^{2}=\mathrm{K}+\mathrm{M}_{\mathrm{ij}} \alpha_{\mathrm{i}} \alpha_{\mathrm{j}}
$$

Constitutive equation: The constitutive relations of all layers of the Glulam can include the material nonlinear effect by using the incremental form of Hooke's law. That is:

$$
\left\{\mathrm{d} \sigma^{\prime}\right\}_{1}=\left[\mathrm{Q}^{\prime}\right]_{1}\left\{\mathrm{~d} \varepsilon^{\prime}\right\}_{1}
$$

In eqn. 20,1 is the layer of Glulam, $\left\{d \sigma^{\prime}\right\}_{1}=$ $\left\{\mathrm{d} \sigma_{\mathrm{x}}, \mathrm{d} \sigma_{\mathrm{y}}, \mathrm{d} \tau_{\mathrm{xy}}\right\},\left\{\mathrm{d} \varepsilon^{\prime}\right\}_{1}=\left\{\mathrm{d} \varepsilon_{\mathrm{x}}, \mathrm{d} \varepsilon_{\mathrm{y}}, \mathrm{d} \gamma_{\mathrm{xy}}\right\}$ are the stress and strain increment vectors between the layers, assuming the interlayer bonding of the Glulam is in good condition and $\left\{Q^{\prime}\right\}_{1}$ is the constitutive matrix of elastic, elastic-plastic and the post failure stage at different stress levels. The following relationship between force and strain can be obtained after superposition of the constitutive equation of each layer:

$$
\{\mathrm{dN}\}=\sum_{1=1}^{\mathrm{n}}\left[\mathrm{Q}^{\prime}\right]_{1} \mathrm{t}_{1}\left\{\mathrm{~d}^{\prime}\right\}_{1}
$$

In eqn. $21,\{d N\}=\left\{N_{x}, N_{y}, N_{x y}\right\}$ is the residual force vector which acts on each layer, $t_{1}$ is the thickness of the 1 layer of Glulam and $n$ is the number of layers.

After the failure criterion and constitutive equation are established, according to the general analysis process of nonlinear finite elements, commercialized ABAQUS, ANSYS, or other software can be used to carry out the material non-linear finite element analysis of Glulam to analogue simulate its mechanical behaviours.

Deformation and stress cloud picture of specimens: The results of the finite element numerical simulation appeared as mainly tackless damage, which were difficult to simulate the fracture damage. The simulation results of ultimate load and mid-span ultimate deformation were consistent with the test results. It could be seen from the structure deformation and stress cloud picture that the maximum stress ruptures of the specimens generally appeared on the mid-span loaded parts and both ends of the support parts. This meant the upper portion of the specimen was in tension, while the lower portion was in pressure and the stress in the mid-span and support parts was relatively concentrated, leading to the tackless phenomenon.

When the thickness was the same but the specimen's span was different, the stress changes were nearly the same and only the stress direction was different. This demonstrated that the bearing capacity under vertical loading was different from that under parallel loading and the colour of the stress cloud picture under vertical loading was deeper than under parallel loading. The simulation results were consistent with the test results. The finite element numerical analysis of typical deformation and stress cloud pictures are shown in Figs. 9 and 10 .

When the span and thickness of the specimens were the same but the assembly structure was different, the stress changes under vertical loading and parallel loading were similar, except with slightly different colours, which are shown in Figs. 11 and 12. 

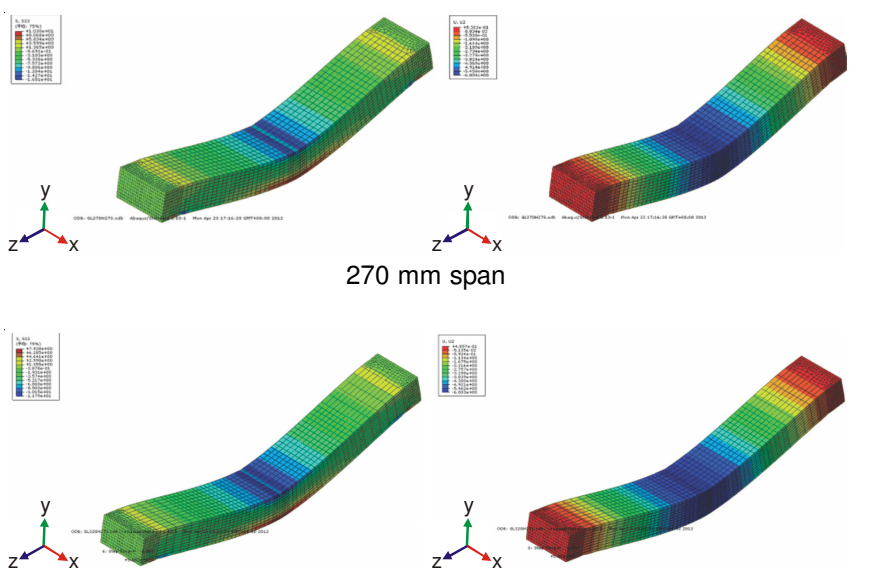

$320 \mathrm{~mm}$ span
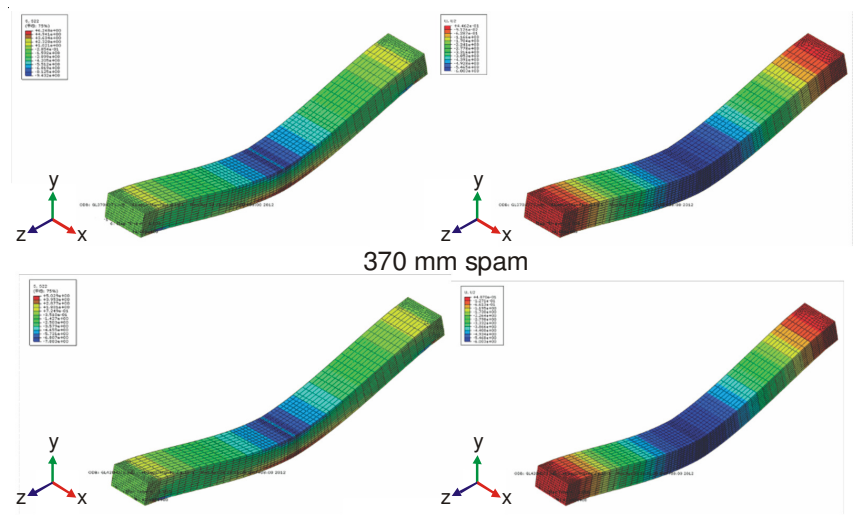

$420 \mathrm{~mm}$ spam

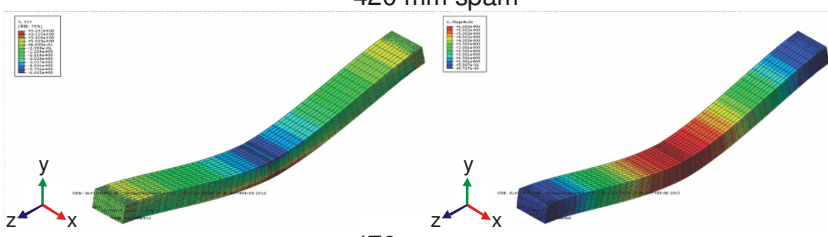

$470 \mathrm{~mm}$ spam

Fig. 9. Y direction stress cloud-displacement picture of glass fiber cloth reinforced Glulam $27 \mathrm{~mm}$ thick under vertical loading

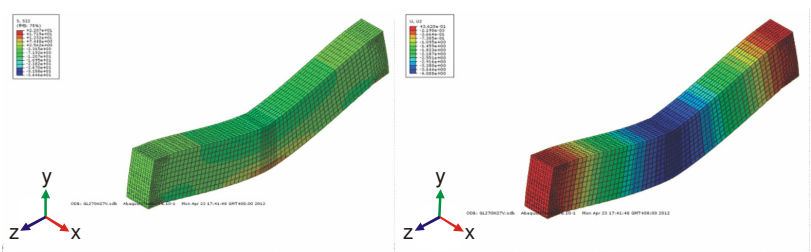

$270 \mathrm{~mm}$ spam
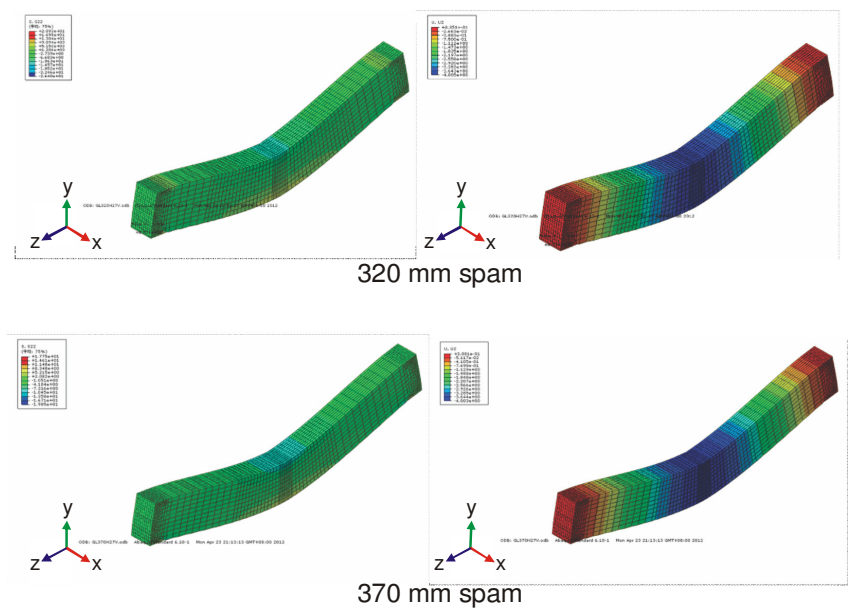

$370 \mathrm{~mm}$ spam
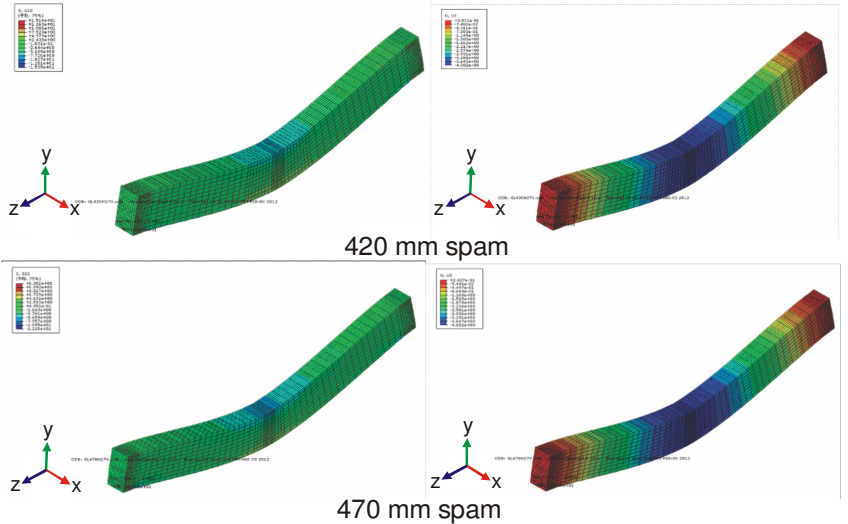

Fig. 10. Y direction stress cloud-displacement picture of glass fiber cloth reinforced Glulam $27 \mathrm{~mm}$ thick under parallel loading
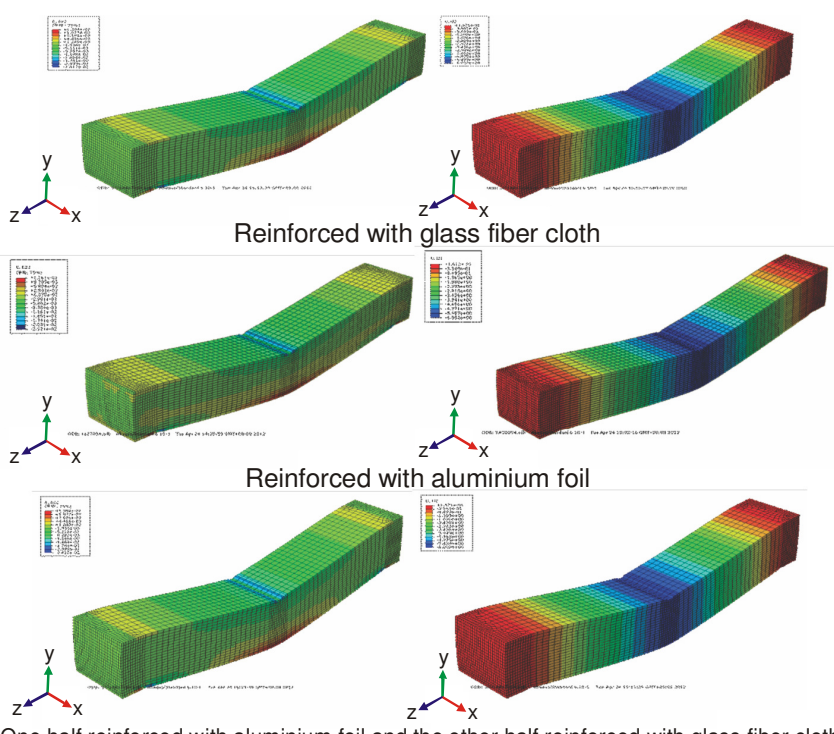

One half reinforced with aluminium foil and the other half reinforced with glass fiber clo
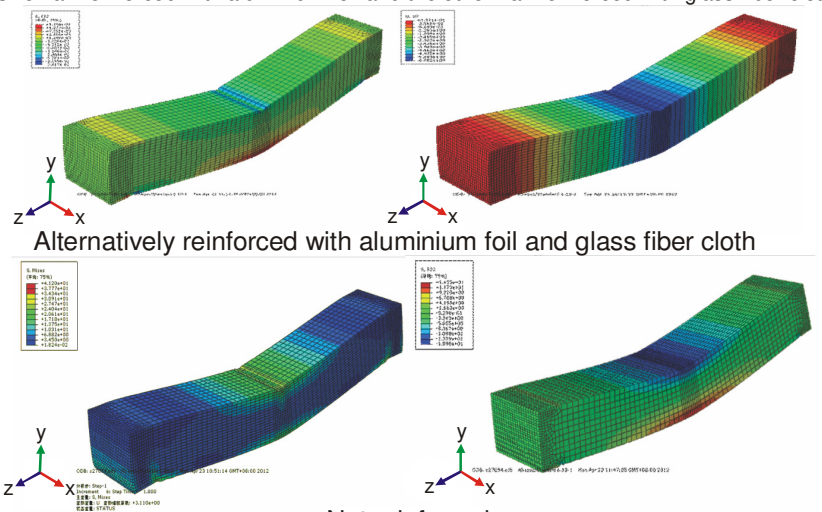

Not reinforced

Fig. 11. Y direction stress cloud-displacement picture of reinforced Glulam with $54 \mathrm{~mm}$ thick and $270 \mathrm{~mm}$ span under vertical loading

\section{Conclusions}

- Specimens initially showed signs of separation from the adhesive layers and then the cracks expanded to the reinforcing glass fiber cloth and aluminum foil and finally expanded to the wood veneers. Essentially, the fracture modes were sliding type failures at first, followed by tearing type failures under vertical loads.

- The specimens were characterized as having open fractures, but the morphological changes were smaller under 

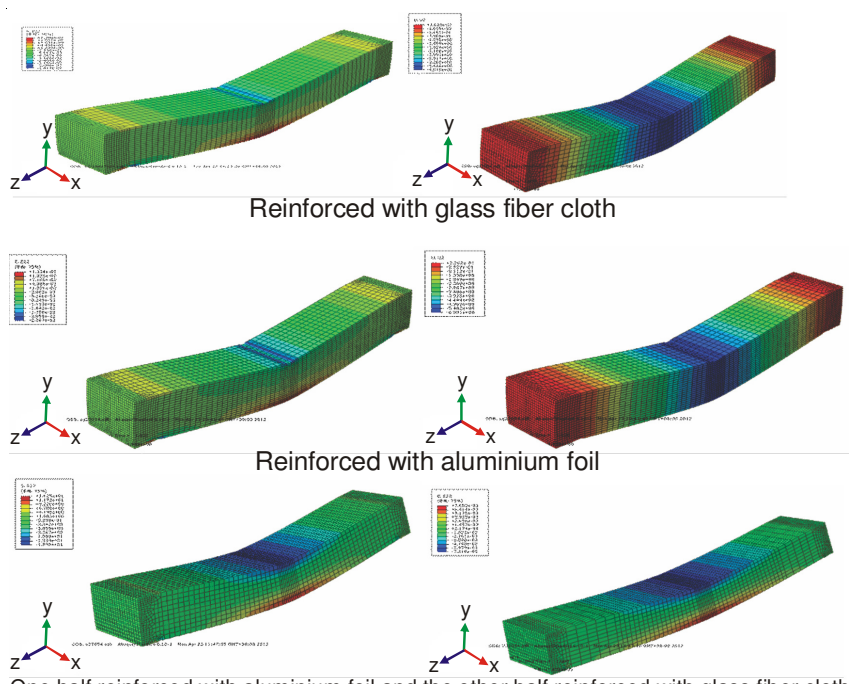

One half reinforced with aluminium foil and the other half reinforced with glass fiber cloth

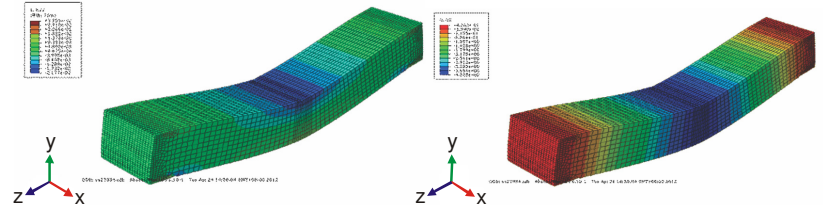

Alternatively reinforced with aluminium foil and glass fiber cloth

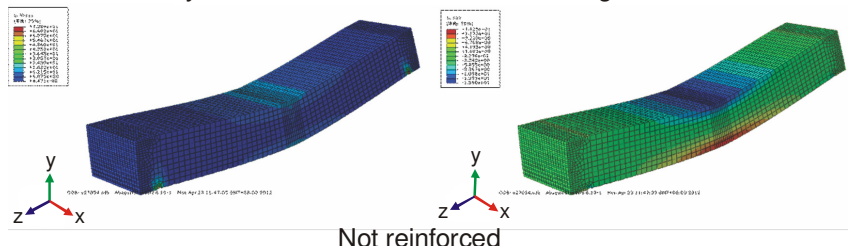

Fig. 12. Y direction stress cloud-displacement picture of reinforced Glulam $54 \mathrm{~mm}$ thick with $270 \mathrm{~mm}$ span under parallel loading

parallel loading than under vertical loading. The reinforcing materials had no impact on the fracture modes of the Glulam under parallel loads.

- The specimens presented linear plastic deformations before fracturing whether under vertical loading or parallel loading. Also, the fracture modes were in a relatively straight line under parallel loading, which was a brittle fracture, while the fracture types shown under vertical loads were due to the wood fibers tearing. It is tremendously more effective to use vertical loading to support a load in order to make the timber structure safe.

- The simulation results of the nonlinear finite element analysis showed that both aluminum foil and glass fiber cloth had an obvious reinforcing effect. Furthermore, the ultimate bearing capacity decreased when the specimen span increased, the ultimate bearing capacity increased when the specimen thickness increased and the gap of ultimate bearing capacity reduced gradually when the specimen length increased with different thicknesses. This proved that thickness and length have an interactive effect on the ultimate bearing capacity. In other words, the simulation results were consistent with the test results.

\section{ACKNOWLEDGEMENTS}

This work was financially supported by the Plan Projects of Introducing Advanced International Forestry Technology (2012-4-27), the Program for New Century Excellent Talents in University (NCET-12-0725) and the Outstanding Youth Projects of Hunan Province Education Department (12B134).

\section{REFERENCES}

1. Y.F. Yin, X.M. Jiang, J.X. Lu and H.Z. Su, China Wood Ind., 15, 3 (2001).

2. X.M. Wan, Z.H. Jiang and B.H. Fei, Word Forestry Res., 16, 62 (2003).

3. Z.F. Zhang and X. Zhang, China Forest Products Ind., 39, 19 (2012).

4. W.X. Peng, Y.Q. Wu, S.B. Wu, D.Q. Zhang and H. Cheng, Trans. China Pulp Paper, 24, 42 (2009).

5. Z.F. Zhang and X.Y. Zhou, Building Struct., 42, 139 (2012).

6. M. Spence, J. Inst. Wood Sci., 16, 24 (2002).

7. C. Tenorio, R. Moya and F. Muñoz, J. Wood Sci., 57, 134 (2011).

8. R.C. Moody, Forest Products J., 20, 81 (1970).

9. Z.P. Shao, H.Q. Pen and Z.H. Jiang, Scientia Silvae Sinicae, 39, 119 (2003).

10. P.R. Blankenhorn, J.P. Labosky, J.J. Janowiak, H.B. Manbeck, D.A. Webb and R.T. Baileys, Forest Products J., 49, 87 (1999).

11. B. Ozarska, Wood Sci. Technol., 33, 341 (1999).

12. J.F. Davalos, S.S. Sonti, Y. Kim and R.C. Moody, Strength and Stiffness of Reinforced Yellow-Poplar Glued-Laminated Beams, US Department of Agriculture, Forest Service, Forest Products Laboratory (1997).

13. W.G. Davids, E. Nagy and M.C. Richie, J. Bridge Eng., 13, 183 (2008).

14. D. Toksoy, G. Çolakoglu, I. Aydin, S. Çolak and C. Demirkir, Build. Environ., 41, 872 (2006).

15. A.M.J.P. Barreto, R.D.S.G. Campilho, M.D. Moura, J.J.L. Morais and C.L. Santos, J. Adhes., 86, 630 (2010).

16. M. Romani, Bautechnik, 79, 216 (2002).

17. N. Ayrilmis, T. Dundar, Z. Candan and T. Akbulut, BioResources, 4, 1536 (2009).

18. S. Aicher and D. Ohnesorge, Eur. J. Wood Wood Prod, 69, 143 (2011).

19. Z. Hashin, J. Appl. Mech., 47, 329 (1980).

20. B. Dejak, A. Mlotkowski and M. Romanowicz, J. Prosthet. Dent., 98, 89 (2007).

21. K.S. Liu and S.W. Tsai, Compos. Sci. Technol., 58, 1023 (1998). 